\title{
Mobile air monitoring data-processing strategies and effects on spatial air pollution trends
}

\author{
H. L. Brantley ${ }^{1,2}$, G. S. W. Hagler ${ }^{1}$, E. S. Kimbrough ${ }^{1}$, R. W. Williams ${ }^{3}$, S. Mukerjee $^{3}$, and L. M. Neas ${ }^{4}$ \\ ${ }^{1}$ US Environmental Protection Agency, Office of Research and Development, National Risk Management Research \\ Laboratory, Research Triangle Park, North Carolina, USA \\ ${ }^{2}$ Student Services Contractor, Research Triangle Park, North Carolina, USA \\ ${ }^{3}$ US Environmental Protection Agency, Office of Research and Development, National Exposure Research Laboratory, \\ Research Triangle Park, North Carolina, USA \\ ${ }^{4}$ US Environmental Protection Agency, Office of Research and Development, National Health and Environmental Effects \\ Research Laboratory, Chapel Hill, North Carolina, USA
}

Correspondence to: G. S. W. Hagler (hagler.gayle@epa.gov)

Received: 1 November 2013 - Published in Atmos. Meas. Tech. Discuss.: 5 December 2013

Revised: 15 May 2014 - Accepted: 7 June 2014 - Published: 22 July 2014

\begin{abstract}
The collection of real-time air quality measurements while in motion (i.e., mobile monitoring) is currently conducted worldwide to evaluate in situ emissions, local air quality trends, and air pollutant exposure. This measurement strategy pushes the limits of traditional data analysis with complex second-by-second multipollutant data varying as a function of time and location. Data reduction and filtering techniques are often applied to deduce trends, such as pollutant spatial gradients downwind of a highway. However, rarely do mobile monitoring studies report the sensitivity of their results to the chosen data-processing approaches. The study being reported here utilized $40 \mathrm{~h}$ (>140000 observations) of mobile monitoring data collected on a roadway network in central North Carolina to explore common data-processing strategies including local emission plume detection, background estimation, and averaging techniques for spatial trend analyses. One-second time resolution measurements of ultrafine particles (UFPs), black carbon (BC), particulate matter $(\mathrm{PM})$, carbon monoxide $(\mathrm{CO})$, and nitrogen dioxide $\left(\mathrm{NO}_{2}\right)$ were collected on 12 unique driving routes that were each sampled repeatedly. The route with the highest number of repetitions was used to compare local exhaust plume detection and averaging methods. Analyses demonstrate that the multiple local exhaust plume detection strategies reported produce generally similar results and that utilizing a median of measurements taken within a specified route segment (as opposed to a mean) may be sufficient to avoid bias in near-source spatial trends.
\end{abstract}

A time-series-based method of estimating background concentrations was shown to produce similar but slightly lower estimates than a location-based method. For the complete data set the estimated contributions of the background to the mean pollutant concentrations were as follows: BC (15\%), UFPs (26\%), $\mathrm{CO}(41 \%), \mathrm{PM}_{2.5-10}(45 \%), \mathrm{NO}_{2}(57 \%)$, $\mathrm{PM}_{10}(60 \%), \mathrm{PM}_{2.5}(68 \%)$. Lastly, while temporal smoothing (e.g., $5 \mathrm{~s}$ averages) results in weak pair-wise correlation and the blurring of spatial trends, spatial averaging (e.g., $10 \mathrm{~m}$ ) is demonstrated to increase correlation and refine spatial trends.

\section{Introduction}

Air quality research has been revolutionized in recent years by the development and application of mobile platforms capable of resolving air pollutant concentrations in real time. These platforms - including instrumented cars, vans, bicycles, and handheld devices - have been enabled by advancements in air monitoring instrumentation, such as higher time resolution and greater portability, as well as improvements in location resolution using commercially available global positioning systems (GPSs). The mobile measurement strategy has been utilized for a diverse range of applications, which can be loosely categorized as (1) emissions characterization, (2) near-source assessment, and (3) general air quality surveying (Table 1). 
Table 1. Mobile monitoring example applications.

\begin{tabular}{|c|c|c|c|c|}
\hline Category & Example investigations & Measurement platform & Data-processing steps applied & References \\
\hline \multirow[t]{3}{*}{$\begin{array}{l}\text { Emissions } \\
\text { quantification }\end{array}$} & $\begin{array}{l}\text { Determining and comparing } \\
\text { emissions factors from } \\
\text { vehicles under various driving } \\
\text { conditions }\end{array}$ & Electric vehicle & $\begin{array}{l}\text { Local exhaust plume detection, } \\
\text { temporal smoothing }\end{array}$ & Park et al. (2011) \\
\hline & $\begin{array}{l}\text { Evaluating change in emissions } \\
\text { factors after traffic intervention }\end{array}$ & Vehicle & $\begin{array}{l}\text { Local exhaust plume detection, } \\
\text { background standardization, } \\
\text { temporal smoothing }\end{array}$ & Wang et al. (2009) \\
\hline & $\begin{array}{l}\text { Characterizing hydrocarbon } \\
\text { emissions }\end{array}$ & Vehicle & Local exhaust plume detection & Pétron et al. (2012) \\
\hline \multirow{4}{*}{$\begin{array}{l}\text { Near-source air } \\
\text { quality gradients } \\
\text { and mitigation } \\
\text { strategy evaluation }\end{array}$} & Roadside barrier impacts & Electric vehicle & $\begin{array}{l}\text { Local exhaust plume detection, } \\
\text { background standardization, } \\
\text { spatial smoothing }\end{array}$ & Hagler et al. (2012) \\
\hline & Near-road gradients & Electric vehicle & $\begin{array}{l}\text { Time alignment optimization, local } \\
\text { exhaust plume detection, background } \\
\text { standardization, spatial smoothing }\end{array}$ & $\begin{array}{l}\text { Kozawa et al. (2009), } \\
\text { Choi et al. (2012) }\end{array}$ \\
\hline & $\begin{array}{l}\text { Assessing contribution of traffic } \\
\text { in street canyons to } \\
\text { concentration above } \\
\text { background }\end{array}$ & Backpack & $\begin{array}{l}\text { Background standardization, } \\
\text { spatial smoothing }\end{array}$ & Zwack et al. (2011a, b) \\
\hline & $\begin{array}{l}\text { Characterizing spatial and } \\
\text { temporal variation of near-road } \\
\text { gradients }\end{array}$ & Recreational vehicle & Temporal and spatial smoothing & $\begin{array}{l}\text { Padró-Martínez et al. } \\
\text { (2012) }\end{array}$ \\
\hline \multirow{4}{*}{$\begin{array}{l}\text { General air quality } \\
\text { surveying }\end{array}$} & $\begin{array}{l}\text { Change in air quality in city of } \\
\text { Hamilton, 2005-2010 }\end{array}$ & Van & $\begin{array}{l}\text { Background standardization, } \\
\text { temporal smoothing }\end{array}$ & $\begin{array}{l}\text { Adams et al. (2012), } \\
\text { Wallace et al. (2009) }\end{array}$ \\
\hline & $\begin{array}{l}\text { Characterizing pollution in } \\
\text { low-income neighborhoods in } \\
\text { Ghana }\end{array}$ & Handheld & $\begin{array}{l}\text { Background standardization, } \\
\text { spatial smoothing }\end{array}$ & $\begin{array}{l}\text { Arku et al. (2008), } \\
\text { Dionisio et al. (2010) }\end{array}$ \\
\hline & $\begin{array}{l}\text { Spatial variability of urban air } \\
\text { quality }\end{array}$ & Bicycle & $\begin{array}{l}\text { Background standardization, } \\
\text { spatial smoothing }\end{array}$ & Van Poppel et al. (2013) \\
\hline & Characterizing exposure zones & Electric vehicle & Local exhaust plume detection & Hu et al. (2012) \\
\hline
\end{tabular}

Mobile monitoring is often chosen over other methods for its ability to efficiently obtain data at a high spatial resolution under a variety of different conditions. Vehicle emission factor estimation can be conducted using a number of methods, including chassis dynamometer experiments, tunnel studies, and remote sensing, but mobile monitoring methods are often selected because they enable researchers to characterize in-use emissions of individual vehicles under a variety of operating conditions (Park et al., 2011; Wang et al., 2011, 2012; Westerdahl et al., 2009; Wang et al., 2009).

In near-source environments and general air quality surveys, pollutant concentrations attributable to local sources can vary on the scale of tens of meters or smaller. To characterize this spatial variation, dense networks of stationary monitors can be deployed, but mobile monitoring is often preferred because of the increased spatial flexibility (Baldauf et al., 2008; Choi et al., 2012; Durant et al., 2010; Hagler et al., 2012; Kozawa et al., 2009; Zwack et al., 2011a; Rooney et al., 2012; Westerdahl et al., 2005; Drewnick et al., 2012; Massoli et al., 2012). Broader surveys of ambient air quality are also frequently conducted using mobile monitoring on a scale ranging from neighborhood to country in order to characterize regional concentrations or locate previously unknown hotspots (Hagler et al., 2012, 2010; Arku et al., 2008; Adams et al., 2012; Farrell et al., 2013; Drewnick et al., 2012; Van Poppel et al., 2013; Hu et al., 2012).

In this study we considered three components of mobile monitoring data: (1) local exhaust plumes (i.e., tail pipe exhaust near the sampling inlet), (2) local air pollution (e.g., traffic-related air pollution), and (3) urban-suburban background (i.e., ambient air quality in the area sampled). Gas and aerosol concentrations change in a continuum of spatial and 


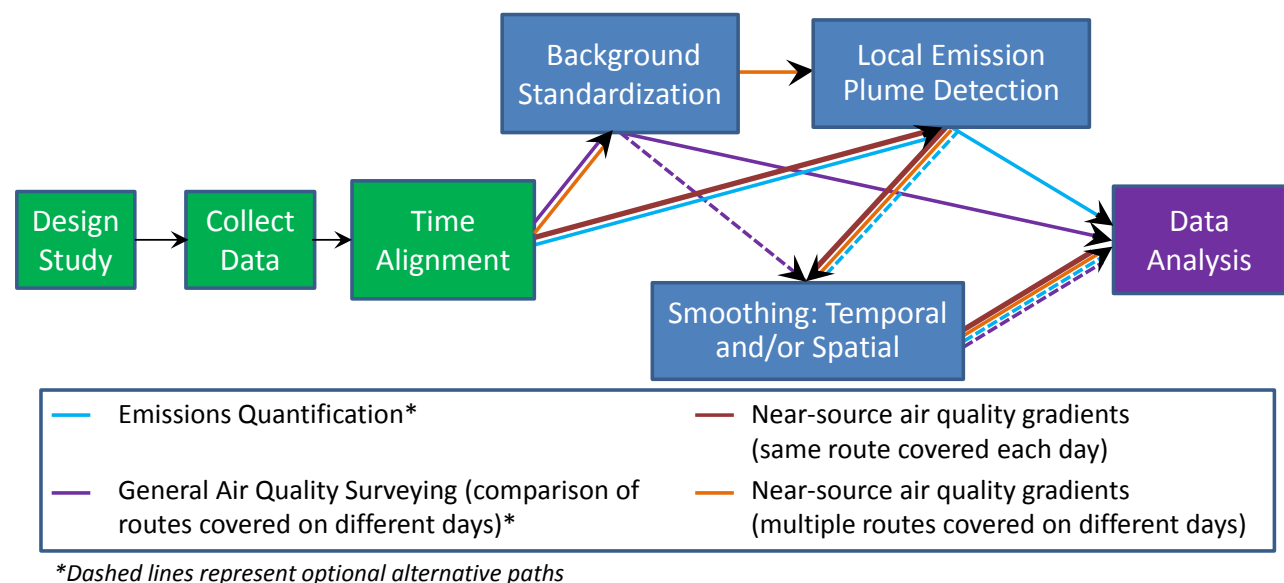

Figure 1. Mobile data-processing steps.

temporal scales, from the point of emissions to ultimate fate in the environment. Our definitions of local exhaust plumes, local air pollution, and background were derived from the various investigations that have utilized mobile monitoring (Table 1). Local exhaust plumes are defined as short-term events characterized by extremely high pollutant concentrations that can be attributed to directly sampling exhaust from a nearby vehicle. Local air pollution is defined here as wellmixed air that is affected by one or more known sources and modulated by local wind, such as air flow from a major highway to local residential areas. Finally, urban-suburban background, henceforth called "background" for simplicity, is defined on the scale of the route $(5-20 \mathrm{~km})$ as representative of ambient air quality conditions without detectable impact of a nearby source.

With this study's primary focus on spatial air pollution trend analysis to characterize general air quality trends and near-source air pollution, analyses to follow demonstrate the effects of various data-processing strategies on resulting trends. In order to extract meaningful information from mobile monitoring data, the full design of the experiment from the point of monitoring route selection to data-processing strategies needs to be taken into account. For example, isolation of local air pollution trends may be simplified by site selection in an environment where roadways surrounding the source of interest have no traffic and the route incorporates a section representative of the background. However, such ideal conditions are rare and often studies need to compensate for local exhaust plumes or imperfect sampling of the background. To isolate key features of interest, past studies have employed a myriad of post-processing strategies (Table 1) to isolate local exhaust plumes, account for the background, and reduce data for visual representation of trends. The selection of post-processing strategies depends on the experimental design and research questions driving the analysis (Fig. 1).
Isolation of local exhaust plumes is of interest for studies that seek to estimate emission factors but also to minimize the impact of sporadic proximate exhaust when determining spatial trends of near-source air pollution. For spatial trend analysis, a variety of strategies have been utilized to minimize bias from incidental local exhaust (Table 2), including using summary statistics less affected by outliers (e.g., percentiles) or algorithms developed to detect brief excursions in the time series. Estimating background is a second key feature of interest to isolate in mobile air monitoring time series. Background air quality often varies diurnally and daily due to meteorology and long-distance transport of pollution. Accounting for the variable background may be conducted through optimal sampling design where an area representative of background is frequently sampled (e.g., Van Poppel et al., 2013). However, when a route completion exceeds the time frame within which the regional background changes or comparisons are being made between multiple routes measured on different days, additional strategies are needed. An alternative approach is to assume the baseline of the time series - represented simply as a low percentile of the data range or a more sophisticated time-varying baseline - is representative of background.

As a final data-processing step, temporal or spatial smoothing is often applied either to reduce variation due to changes in the atmosphere or more effectively display trends (Westerdahl et al., 2005; Weijers et al., 2004; Pirjola et al., 2012). Applying a rolling median or mean can be used to maintain the temporal resolution while reducing the amount of instrument noise and influence of extreme outliers. Aggregating the data to a longer time window can be used to reduce the degree of autocorrelation among the measurements. Types of spatial smoothing include calculating median or mean values along fixed length intervals of the route or within a fixed radius of locations of interest.

Recently, efforts have been made to study the mobile monitoring approach. For example, Van Poppel et al. (2013) 
Table 2. Mobile data-processing methods.

\begin{tabular}{|c|c|c|}
\hline Category & Method description & References \\
\hline \multirow{5}{*}{$\begin{array}{l}\text { Background } \\
\text { estimation }\end{array}$} & Designation of background zone & $\begin{array}{l}\text { Hagler et al. (2012), Van Poppel et al. } \\
\text { (2013) }\end{array}$ \\
\hline & Average of fixed monitoring sites & Arku et al. (2008), Dionisio et al. (2010) \\
\hline & $1 \mathrm{~min}$ or $5 \mathrm{~min} 5$ th percentile & Bukowiecki et al. (2002) \\
\hline & $\begin{array}{l}\text { Assumption that all of the measurements lower than the most } \\
\text { frequent measurement are background }\end{array}$ & Kolb et al. (2004) \\
\hline & $\begin{array}{l}\text { Inclusion of a smooth function of time over each sampling shift as } \\
\text { a term in a linear regression }\end{array}$ & Zwack et al. (2011b, a) \\
\hline \multirow[t]{5}{*}{$\begin{array}{l}\text { Local exhaust } \\
\text { plume detection }\end{array}$} & $\begin{array}{l}\text { Calculate standard deviation of measurements below the median } \\
\left(\sigma_{\mathrm{b}}\right) \text {. Flag any measurement more than } 3 \sigma_{\mathrm{b}} \text { greater than the pre- } \\
\text { vious measurement. Flag all measurements }>3 \sigma_{\mathrm{b}}+\sqrt{n} \times \sigma_{\mathrm{b}} \text { from } \\
\text { the last non-flagged measurement, where } n \text { is the number of points } \\
\text { since the last non-flagged measurement (UFPs }{ }^{\mathrm{a}} \text { and } \mathrm{CO}_{2}^{\mathrm{b}} \text { ). }\end{array}$ & Drewnick et al. (2012) \\
\hline & $\begin{array}{l}\text { Modified } 5 \mathrm{~s} \text { running coefficient of variance, with maximum value } \\
\text { of } 2\left(\mathrm{UFPs}^{\mathrm{a}}\right)\end{array}$ & Hagler et al. (2012) \\
\hline & Smoothed rolling minimum $\left(\mathrm{CO}_{2}^{\mathrm{b}}, \mathrm{NO}^{\mathrm{c}}\right)$ & Kolb et al. (2004) \\
\hline & Rolling 25th percentile $\left(\mathrm{UFPs}^{\mathrm{a}}, \mathrm{NO}^{\mathrm{c}}, \mathrm{PB}-\mathrm{PAH}^{\mathrm{d}}, \mathrm{CO}^{\mathrm{f}}, \mathrm{PM}_{2.5}^{\mathrm{g}}\right.$ ) & Choi et al. (2012) \\
\hline & $\begin{array}{l}\text { Video records checked at times when pollution concentrations } \\
\text { peaked at } \geq 2 \text { observed background concentrations }\left(B C^{e}, N^{c} \text {, }\right. \\
\left.U_{F P s}{ }^{a}, P B-P A H^{d}\right)\end{array}$ & Kozawa et al. (2009) \\
\hline
\end{tabular}

evaluated how many sampling route repeats were required to develop a representative data set. However, a rigorous examination of mobile monitoring data-processing steps and the implications for the derived results is needed. This study utilizes a robust multipollutant mobile monitoring data set collected on a roadway network in North Carolina, USA, to evaluate common data-processing methods, including local exhaust plume detection, background estimation, and spatial and temporal smoothing. The data set consists of $40 \mathrm{~h}$ of mobile monitoring data collected during weekday morning rush hour on 24 days and spanning 12 routes that covered areas of traffic delay, high traffic volume, transit routes, and urban background.

\section{Methods}

\subsection{Experimental data}

An intensive mobile monitoring campaign was conducted in the Research Triangle area of North Carolina in the summer of 2012 as part of the Research Triangle Area Mobile Source Emission Study (RAMSES). Measurements were collected using a converted all-electric PT Cruiser. Six instruments were securely installed on board the vehicle: an engine exhaust particle sizer (EEPS) (model 3090, TSI, Shoreview, MN, USA) which provided size-resolved ultrafine and accumulation-mode particle counts, an aerodynamic particle sizer (APS) (model 3321, TSI, Shoreview, MN, USA) for size-resolved particle counts in fine to coarse mode, a portable Aethalometer (AE42, Magee Scientific, Berkeley, CA, USA) that measured black carbon (BC), a dual quantum cascade laser (QCL) (Aerodyne Research Inc., Billerica, MA, USA) that measured carbon monoxide (CO), a cavityattenuated phase shift (CAPS) monitor that measured nitrogen dioxide $\left(\mathrm{NO}_{2}\right)$ (Aerodyne Research Inc., Billerica, MA, USA), and a nondispersive infrared (NDIR) gas analyzer that measured carbon dioxide $\left(\mathrm{CO}_{2}\right)$ (LI-COR 820, LI-COR Biosciences, Lincoln, NE, USA). Due to an observation that the $\mathrm{CO}_{2}$ data exhibited inexplicable periodic substantial drops in concentration during some of the runs, it was not incorporated into the analyses. 
Calibration checks were routinely performed before and after each run. All instruments utilized minimal tubing length $(<2 \mathrm{~m})$ and pulled from manifolds connected to two colocated inlets mounted through a side passenger window location. Particle instruments utilized antistatic tubing with minimal bends to avoid particle loss. Further information on the general sampling vehicle setup is available in Hagler et al. (2010). Wind speed and direction were measured with a highly sensitive three-dimensional ultrasonic anemometer (model 81000, RM Young Company, Traverse City, Michigan) placed at a stationary sampling site on each route.

For the current instrument setup, the time between a concentration change (high-efficiency particulate air filter for particle instruments, gas standard for gas instruments) at the inlet and visual inspection of instrument response ranged from 0 to $5 \mathrm{~s}$ for both real-time gas and particle instruments. The response time of the QCL (CO) and APS (particle count in fine to coarse range) was less than $1 \mathrm{~s}$, the CAPS $\left(\mathrm{NO}_{2}\right)$ and Aethalometer (BC) was $4 \mathrm{~s}$, and the EEPS (UFPs) was $5 \mathrm{~s}$.

After applying the lags determined using the concentration change at the inlet, the correlation between the measurements at various time lags was used to fine-tune the alignment. Because the pollutants are co-emitted, the best estimate of the difference in response times between the instruments can be assumed to correspond with the lag time that produces the maximum correlation coefficient (Choi et al., 2012). CO was chosen as the reference measurement because the quantum cascade laser was the most sensitive instrument with the fastest response time. Because the primary source of $\mathrm{CO}$ and $\mathrm{BC}$ in the study area was vehicle exhaust, it was assumed that the maximum correlation would occur when the measurements were perfectly aligned. The measured BC concentration was found to lag the $\mathrm{CO}$ concentration by $3 \mathrm{~s}$. The other particle instruments were also found to lag the $\mathrm{CO}$ measurement by $3 \mathrm{~s}$. The only pollutant measured that was not strongly correlated with $\mathrm{CO}$ at a specific lag time was $\mathrm{NO}_{2}$; however, $\mathrm{NO}_{2}$ was strongly correlated with UFPs at a lag of $0 \mathrm{~s}$, so the lag used for UFPs $(3 \mathrm{~s})$ was also applied to $\mathrm{NO}_{2}$.

The campaign included 12 routes within Wake, Durham, and Orange counties, North Carolina (Fig. 2). The routes covered areas that had previously been classified using modeled traffic data as areas of traffic delay, high traffic volume, transit routes, high signal light density, and urban area. Mobile monitoring was conducted during morning rush hour (07:00-10:30) on 24 weekdays between 23 August and 11 October 2012. Each run consisted of approximately an hour and a half of mobile sampling and $45 \mathrm{~min}$ of stationary sampling. Each route was covered on two sampling days with at least three laps per day. The routes ranged from 5.2 to $18.1 \mathrm{~km}$ in length.

\subsection{Data-processing methods}

Mobile monitoring data were processed and displayed using MATLAB (2012), ArcGIS (ESRI, 2011), and R version 2.15.1 (R Core Team, 2012) along with the R packages ggplot2 (Wickham, 2009), openair (Carslaw and Ropkins, 2012), and mcgv (Wood, 2003). A noise-reduction algorithm was applied to black carbon concentrations to reduce the frequency of negative values (Hagler et al., 2011). Examples of near-source air quality gradients and general air quality surveying were selected to illustrate the implications of the following data-processing steps: background standardization, local exhaust plume detection, spatial smoothing, and temporal smoothing.

Four methods of removing the influence of local exhaust plumes were compared: the running coefficient of variation (COV) method used by Hagler et al. (2012), the standard deviation of the background (SD) method used by Drewnick et al. (2012), the rolling 25 th percentile method used by Choi et al. (2012), and aggregating the data by route segment using outlier-resistant statistics such as the median. The first two methods - the COV method (Hagler et al., 2012) and the SD method (Drewnick et al., 2012) - are both methods of detecting and flagging local exhaust plumes. For studies characterizing near-source air pollution spatial gradients, one approach may be to remove these flagged periods to avoid confounding influence from side-road traffic. Studies focused on personal or localized exposure, however, may not want to remove the influence of the local exhaust plumes. For studies emphasizing emissions characterization, the time periods where local exhaust is detected may be of most interest to isolate and further analyze. These methods are most effective for conditions where an individual vehicle's emissions causes a significant deviation in an otherwise low-emissions environment, such as a truck passing the mobile monitoring vehicle on a low-traffic residential road. In recent history, these approaches have been developed specifically for understanding local-scale air pollution effects from a nearby source, such as a major roadway, with the mobile sampling vehicle being driven along low-traffic side roads. Applying these approaches in environments with higher traffic, such as while driving on highways, likely only detects major outliers as the within-source pollutant levels are likely consistently high and dynamic. Measurements of local exhaust tend to be both higher and more variable than measurements of well-mixed air. Both the COV method (Hagler et al., 2012) and the SD method (Drewnick et al., 2012) rely on the high variability as well as the magnitude of measurements of local exhaust. The running COV method (Hagler et al., 2012) was developed using UFP concentrations and consists of calculating the rolling $5 \mathrm{~s}$ standard deviation ( $2 \mathrm{~s}$ before and after the center data point) and dividing it by the mean concentration of the sampling run. The 99th percentile of the calculated COV is used as a threshold (in Hagler et al. (2012) the threshold COV for UFPs was 2) and any data points with a COV above 


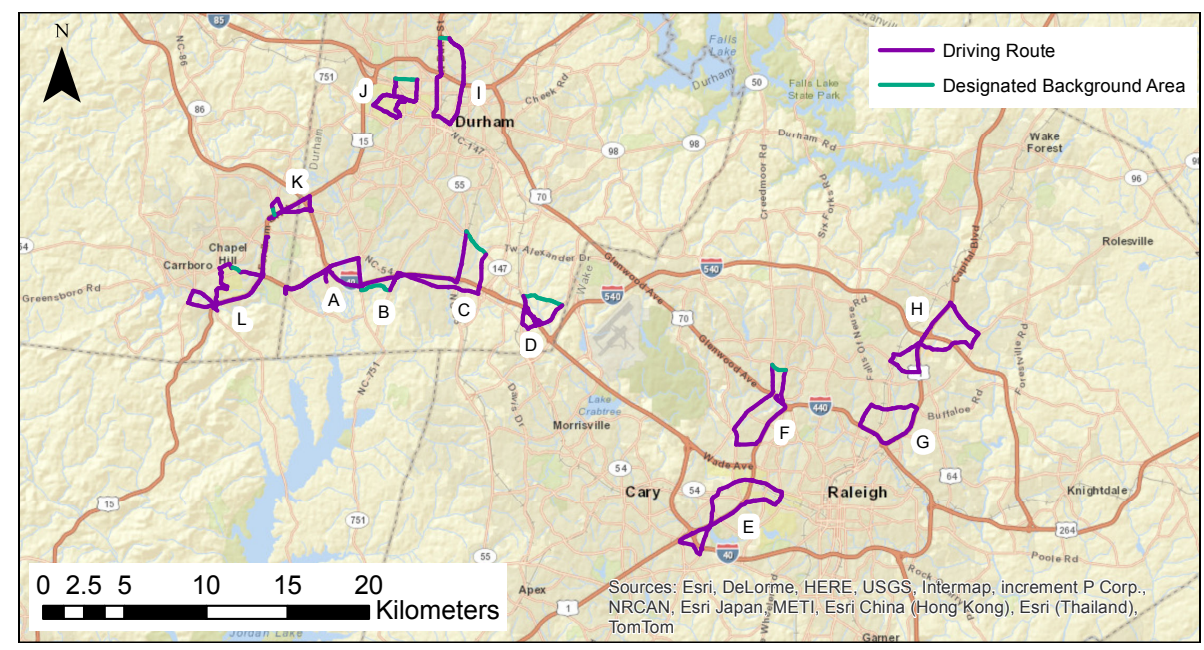

Figure 2. Map of all routes and designated background areas. Background areas were designated for 8 of the 12 routes that had identifiable low-traffic roads distant from known sources. Routes are labeled A-L.

this threshold are flagged along with the data points $2 \mathrm{~s}$ before and after. In the SD method (Drewnick et al., 2012), the standard deviation of measurements (UFPs or $\mathrm{CO}_{2}$ ) below the median is calculated $\left(\sigma_{\mathrm{b}}\right)$. Any measurement more than $3 \sigma_{\mathrm{b}}$ greater than the previous measurement is flagged. Subsequently, all measurements with concentration $C_{i}$ that meets the following criteria are flagged as local exhaust plumes:

$C_{i}>C_{\mathrm{uf}}+3 \sigma_{\mathrm{b}}+\sqrt{n} \times \sigma_{\mathrm{b}}$,

where $C_{\mathrm{uf}}$ is the concentration of the last unflagged measurement and $n$ is the number of measurements between $C_{\mathrm{uf}}$ and $C_{i}$.

The rolling 25th percentile method (Choi et al., 2012) does not detect the local exhaust plumes but is used to reduce their effect on spatial gradients and involves calculating the 25th percentile of various time windows. Choi et al. (2012) used a $53 \mathrm{~s}$ time window ( $26 \mathrm{~s}$ before and after the center data point) when the sampling vehicle was more than $1 \mathrm{~km}$ from away

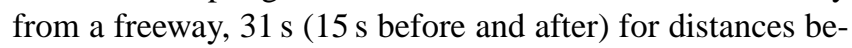
tween $300 \mathrm{~m}$ and $1 \mathrm{~km}$, and $3 \mathrm{~s}$ (1 $\mathrm{s}$ before and after) within $300 \mathrm{~m}$ of a freeway. Because the majority of the data used in this comparison were between $300 \mathrm{~m}$ and $1 \mathrm{~km}$, a $31 \mathrm{~s}$ window was used for the entire data set to simplify the calculation. One final method of reducing the effect of local exhaust plumes on spatial gradient estimations is to use outlierresistant statistics when aggregating data by route segment such as the median instead of the mean.

A single run conducted on 11 October 2012 on route B, was chosen to compare these methods because of the large number of laps conducted (12) and favorable wind conditions (from the highway towards the transect). The mean wind speed during mobile sampling was $0.56 \mathrm{~m} \mathrm{~s}^{-1}$ and the mean wind direction was $285^{\circ}$ (from the NW). The route included a section of highway with an annual average daily traffic (AADT) amount of 109000 , an approximately $900 \mathrm{~m}$ transect running at an angle to the highway with moderate traffic (AADT 32000 ), a low-traffic road considered urban background, and a shorter transect (Fig. 3a). As an illustration, gradients of $\mathrm{CO}, \mathrm{UFPs}, \mathrm{BC}$, and $\mathrm{NO}_{2}$ along the longer transect were used to compare the effect of the local exhaust plume removal methods on the $50 \mathrm{~m}$ mean concentrations and with the $50 \mathrm{~m}$ median concentration of the unfiltered data.

Estimating background concentrations presents a challenge for mobile monitoring studies. For most research groups, replicating the identical instruments (e.g., an engine exhaust particle sizer for ultrafine particles or quantum cascade laser for carbon monoxide) and positioning them in a background location is not feasible. Using alternative instruments for comparison can introduce error into the analysis - for example, from the use of a slower and less sensitive instrument as the benchmark. An alternate approach used in previous mobile monitoring studies (Hagler et al., 2012; Van Poppel et al., 2013) is the location-based method. This method involves defining areas along the route that have low traffic and are far from any known source as background. The mean or median concentrations measured in the designated background sections are considered representative of background concentrations. Another approach is a time-seriesbased method which relies on elements of the time series itself. One time-series-based method is to calculate a single value for each sampling run to be used to normalize the concentrations. This value can be a fixed concentration such as the 1st or 10th percentile of the measurements (Bukowiecki et al., 2002). A rolling minimum is a time series-based approach that produces a time-varying background (Kolb et al., 2004). Zwack et al. (2011a, b) also used a time-varying background estimation based on the time series alone, but instead of estimating background concentrations separately, a smooth function of time over each sampling run was included 

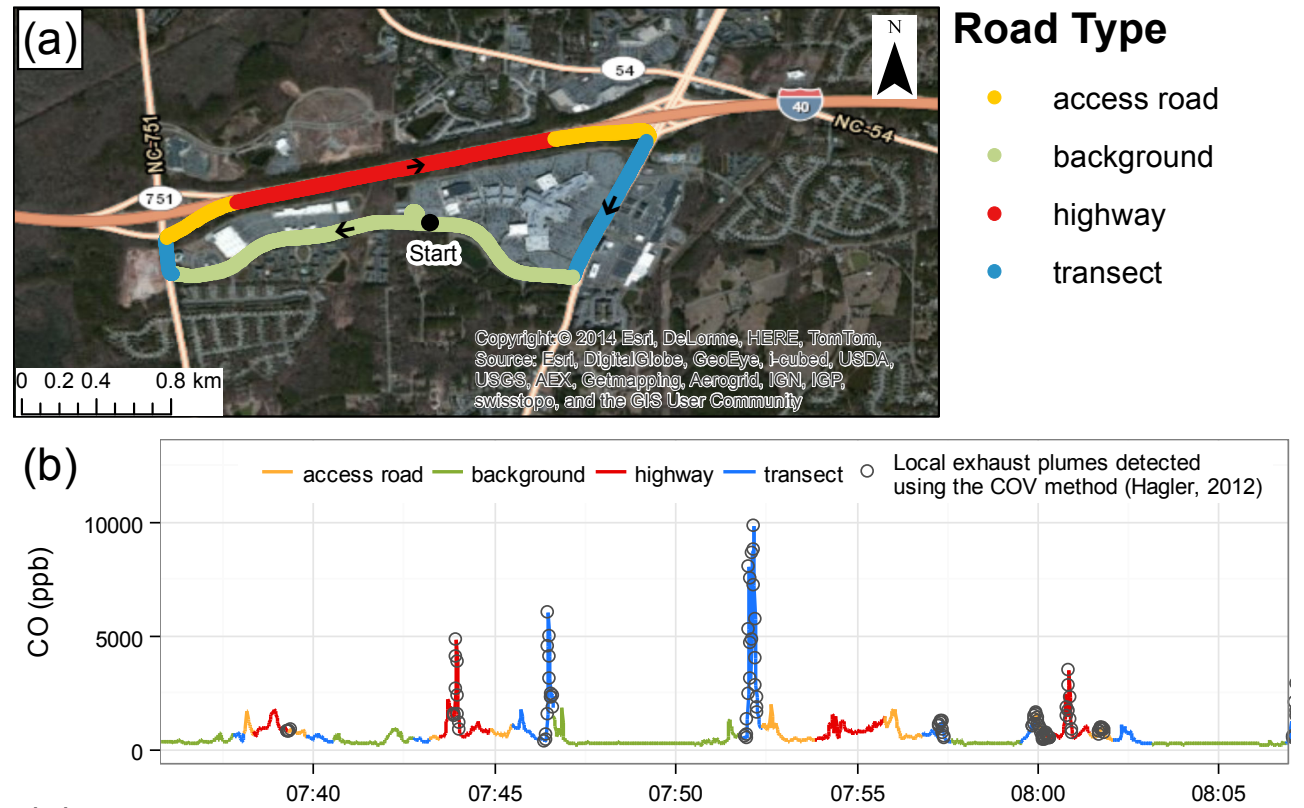

(c)

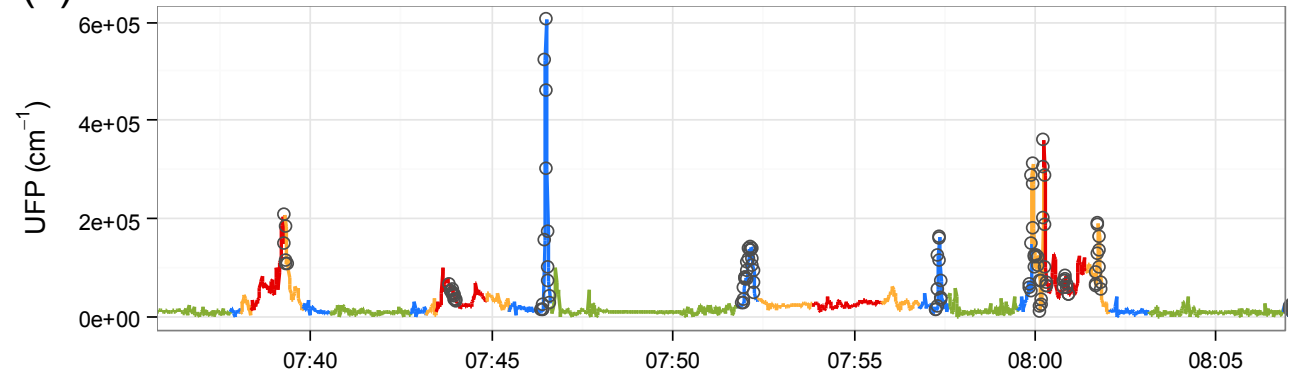

Figure 3. Map of route B used to compare methods detecting local exhaust plumes and smoothing techniques (a), measured CO concentrations (b), and measured UFP concentrations $\left(\mathrm{cm}^{-3}\right)$ during a portion of a sampling run (c). Circles represent local exhaust plumes identified using the COV method (Hagler et al., 2012).

as a term in the linear regression used to determine concentration differences.

The spline of minimums, which is a time-series-based method explored in this study, consists of three steps: (1) applying a rolling $30 \mathrm{~s}$ mean to smooth the measurements, (2) dividing the time series into discrete $10 \mathrm{~min}$ windows and locating the minimum concentration in each window, and (3) fitting a smooth thin plate regression spline through the minimum concentrations. Through the use of a single run conducted on 21 September 2012 on route B with 14 laps, the spline of 10 min minimums was compared with the locationbased method and other time-series-based methods: the use of a low percentile (Bukowiecki et al., 2002), a rolling minimum, and the spline of 5 min minimums (Fig. 5). The spline of 10 min minimums was further compared to the locationbased method using the eight routes with designated background areas. To investigate how well the spline of minimums could estimate the background if the route did not include designated background areas, the concentrations measured in the defined background areas were artificially set to missing before the spline-of-minimums method was applied. The results were then compared to the location-based method.

Ultimately, the results of spatial and temporal smoothing were compared using all of the measurements collected on route $\mathrm{B}$. The average speed of the monitoring vehicle on the route was approximately $10 \mathrm{~m} \mathrm{~s}^{-1}$. The smoothing intervals chosen for comparison were 10,50 , and $100 \mathrm{~m}$ segments; the time intervals necessary to traverse each distance at the average speed equate to 1 (raw data), 5 , and $10 \mathrm{~s}$, respectively. Spearman correlation coefficients were calculated for $\mathrm{CO}$, $\mathrm{BC}$, UFPs, $\mathrm{NO}_{2}$, and $\mathrm{PM}_{2.5}$ before and after temporal and spatial smoothing.

\section{Results and discussion}

The results described in this paper focus on data from a few of the routes and the implications of various data-processing steps. Route B, which had the highest number of repetitions, 


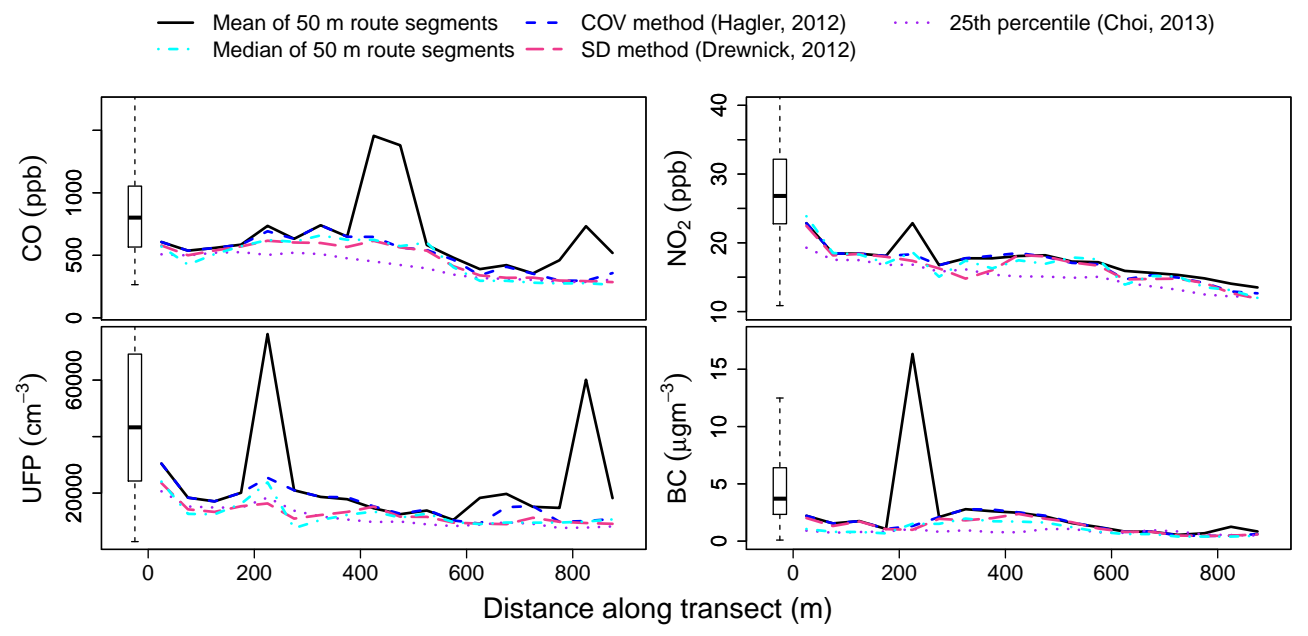

Figure 4. Comparison of the effect of methods of removing the influence of exhaust plumes on transect gradients of CO (a), UFPs (b), $\mathrm{BC}$ (c), and $\mathrm{NO}_{2}$ (d). Lines represent $50 \mathrm{~m}$ means (except for the line which represents the medians) of measurements from the entire run (12 laps). Box plots represent unfiltered concentrations measured on the highway.

was used to compare local exhaust plume detection and spatial and temporal smoothing methods. Eight of the 12 routes - those which had designated background sections - were utilized to compare how background may be estimated using a purely time-series-based approach versus a locationbased approach. The entire data set (12 routes) was utilized to estimate overall background contribution to the measured concentration of each pollutant. The complexity of the preprocessing and analysis of mobile monitoring data precludes a detailed assessment of all study results in this paper.

\subsection{Comparison of methods of local exhaust plume detection}

Four methods of removing the influence of local exhaust plumes were compared: the COV method used by Hagler et al. (2012), the SD method used by Drewnick et al. (2012), the rolling 25th percentile method used by Choi et al. (2012), and aggregating the data by route segment using outlierresistant statistics such as the median. Figure 3 illustrates the potential of local exhaust plumes to affect the characterization of near-source spatial trends. Using the COV method (Hagler et al., 2012) for both CO and UFPs, several local exhaust plumes were identified (Fig. $3 \mathrm{~b}$ and c). Spatially aggregating the measurements without removing the influence of the plumes at 07:46 and 07:53 may erroneously lead to the conclusion that concentrations are generally greater along the transect than on the highway (Fig. 3).

For near-source air monitoring studies, a common analysis is to consider concentrations as a function of distance from the source of interest (e.g., edge of road) (Karner et al., 2010). Similar to previous studies, elevated concentrations of mobile source pollutants were observed on the highway (box plots in Fig. 4), and measured concentrations decreased with increased distance from the highway (Fig. 4). However, the mean $50 \mathrm{~m}$ concentrations along the transect are clearly affected by local exhaust plumes, as is evidenced by the mean concentrations of UFPs, $\mathrm{BC}, \mathrm{NO}_{2}$, and $\mathrm{CO}$ at $250 \mathrm{~m}$ (Fig. 4). Using any of the methods of separating measurements of well-mixed air from local exhaust plumes substantially reduces the influence of these events. The 25th percentile method (Choi et al., 2012) results in the lowest estimates of concentrations along the transect because it affects all of the measurements, not just those influenced by local exhaust. The 25th percentile filter (Choi et al., 2012) also results in the smoothest estimate of the gradient along the transect (Fig. 4).

Another important consideration is that different exhaust plumes contain different pollutant mixtures. For example, the plume that was encountered at $250 \mathrm{~m}$ caused spikes in all four exhaust indicators, while the plume encountered at $800 \mathrm{~m}$ caused increases in CO and UFPs but not in BC or $\mathrm{NO}_{2}$ (Fig. 4). The measurements used as indicators of local exhaust must be chosen carefully to adequately remove the spikes while retaining the majority of the data. For this run, by using both $\mathrm{CO}$ and UFPs as indicators, the spikes in $\mathrm{NO}_{2}$ and $\mathrm{BC}$ were successfully removed.

\subsection{Comparison of background estimation methods}

Several time-series-based methods of estimating background were compared with the location-based method. One timeseries-based method is to calculate a single value for each sampling run using a low percentile of the measurements. However, in the present study over the course of a $2 \mathrm{~h} \mathrm{sam}$ pling period, the baseline of the $\mathrm{CO}$ time series decreased from 400 to $200 \mathrm{ppb}$ (Fig. 5). During this run, the wind speed increased from a mean of $0.3 \mathrm{~m} \mathrm{~s}^{-1}$ during the first half hour 

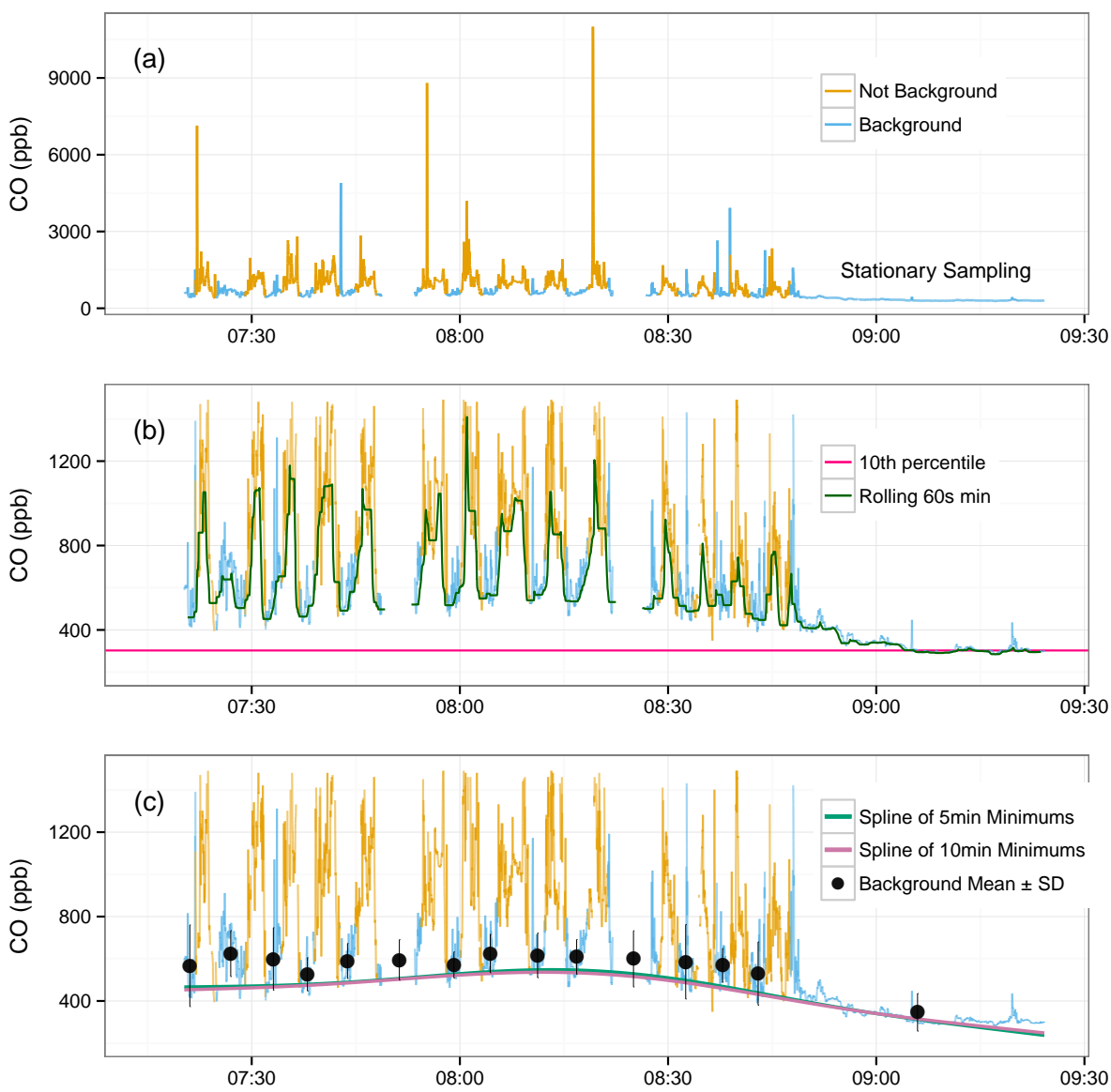

Figure 5. Background estimation methods: (a) example time series; (b) time series methods: running minimum and 10th percentile; (c) location-based method (mean and standard deviation of background areas) and time series methods: spline of 5 min minimums and spline of 10 min minimums. Gaps in the time series are due to quality control checks. Legend definitions are consistent across panels. The limits of the $y$ axis of (b) and (c) have been reduced to more clearly display the baseline.

to a mean of $0.7 \mathrm{~m} \mathrm{~s}^{-1}$ for the last half hour and the wind direction was fairly consistently from the southwest; mean wind direction was 217 and $249^{\circ}$ during the first and last half hour, respectively. The decrease in background concentrations over the $2 \mathrm{~h}$ time span is likely related to an increase in the atmospheric mixing height during the morning period; however further analysis would be required to fully explore the causes of background variation. Depending on the research question and the pollutant of interest, using a single value to normalize the data may introduce unnecessary error. A rolling minimum did not appear to be a good alternative to a fixed concentration. A $60 \mathrm{~s}$ rolling minimum is a better descriptor of variation in well-mixed air concentrations than variation in the background (Fig. 5b). A $300 \mathrm{~s}$ rolling minimum results in a more drastic stair-step pattern which is not descriptive of the change in background over time, which generally changes very gradually. The spline of minimums best represented the smooth change in the time series baseline over time (Fig. 5c), and the choice of time window ( 5 min versus $10 \mathrm{~min}$ ) did not cause a noticeable difference.
The spline of 10 min minimums was used to estimate the background of six pollutants: $\mathrm{BC}, \mathrm{CO}, \mathrm{NO}_{2}, \mathrm{PM}_{2.5}, \mathrm{PM}_{10}$, and UFPs on a total of 16 runs covering 8 routes. The background concentrations were estimated using the spline of minimums and compared with the median concentration measured during each pass of the background (Fig. 6). The spline-of-minimums estimates were positively correlated but consistently underestimated the median of measured background concentrations. The strongest agreement was between the $\mathrm{PM}_{2.5}$ estimates, likely due to the fact that $\mathrm{PM}_{2.5}$ concentrations are least likely to be influenced by incidental traffic in the background areas. Despite the use of the an outlier-resistant statistic, the occurrences of median measured background values that are significantly higher than the background estimated by the spline of minimums are likely a result of traffic in the designated background area or other local sources (e.g., lawnmower emissions).

To investigate whether the spline-of-minimums method could be applied to routes that did not include identifiable background areas, the concentrations measured in the 
background areas were artificially removed (set to missing) and the background was reestimated. The spline-ofminimums method was still able to estimate the background concentrations with the results more evenly distributed around the $y=x$ line (Fig. 6).

The spline of minimums proved to be an effective method for routes spanning a range of distances and under a variety of meteorological conditions. The average wind speed measured during the runs with designated background areas ranged from 0.4 to $1.3 \mathrm{~m} \mathrm{~s}^{-1}$. The wind direction ranged from fairly consistent to highly variable with an average standard deviation of wind direction (Yamartino, 1984) ranging from 30 to $86^{\circ}$. The effectiveness of the spline-of-minimums method at estimating the background concentrations for multiple pollutants across various routes and meteorological conditions will enable researchers to compare routes measured on different days. One of the difficulties in using the locationbased method is determining whether the inclusion of a background section in the route is feasible given the study priorities. By using the spline-of-minimums method, the analysis is simplified.

To illustrate the possibility of comparing different routes sampled on different days, we standardized the background of the concentrations measured on four routes on eight different days by subtracting the estimates produced by the splineof-minimums method from the measured concentrations. We then compared the $\mathrm{PM}_{2.5}$ concentrations with and without background standardization. Before background standardization, the regional background variation obscured the variation in $\mathrm{PM}_{2.5}$ due to the highway (I-40) (Fig. 7a). The $\mathrm{PM}_{2.5}$ concentrations measured on route $\mathrm{B}$ on a highway with an AADT of 109000 were below the 50th percentile when compared with all of the measurements made over the course of the field campaign, while measurements collected on route A on a road with an AADT of 18000 and route $C$ on a road with an AADT of 17000 were all above the 50th percentile (Fig. 7a). After the background was standardized, the influence of the highway traffic, which is an established source of $\mathrm{PM}_{2.5}$, became much more evident: the majority of the measurements collected on highways (AADT $\geq 100000$ ) fall in the higher percentiles of $\mathrm{PM}_{2.5}$ concentrations, and measurements made on roads with less traffic fall in the lower percentiles of the data set (Fig. 7b).

Background standardization will have the greatest effect on measurements of pollutants that have a high regional background concentration relative to the concentrations emitted by the source of interest. The mean of the background concentration of all 24 runs and the contribution of the background to the total concentration was calculated for $\mathrm{BC}$, UFPs, $\mathrm{CO}, \mathrm{NO}_{2}, \mathrm{PM}_{10}$, and $\mathrm{PM}_{2.5}$ using the background estimated using the spline-of-minimums method (Table 3). Of the mobile source pollutants measured in this study, $\mathrm{PM}_{2.5}, \mathrm{PM}_{10}$, and $\mathrm{NO}_{2}$ all fall into the category of coemitted pollutants with high regional background concentrations ( $\geq 50 \%$ of the mean measured concentrations, Table 3 ).
In contrast, $\mathrm{CO}, \mathrm{BC}$, and UFPs can all be classified as coemitted pollutants with low regional background concentrations (Table 3).

Kimbrough et al. (2013), in a near-road study conducted in Las Vegas, Nevada, also found that the background contribution of $\mathrm{NO}_{2}$ to the total concentration was higher than the background contribution of $\mathrm{CO}$ and $\mathrm{BC}$, with measured upwind concentrations approximately 69,63 , and $44 \%$ of downwind concentrations for $\mathrm{NO}_{2}, \mathrm{CO}$, and $\mathrm{BC}$, respectively. The background contributions measured by Kimbrough et al. (2013) are higher than those calculated for the current study, likely because the downwind measurements made by Kimbrough et al. (2013) were collected $20 \mathrm{~m}$ from the road, while many of the measurements in the current study were collected on the highway or on roads with high traffic volume, causing the total concentrations to be higher and the fraction attributable to regional background to be lower. Upwind concentrations of UFPs measured by Hagler et al. (2009) were roughly $30 \%$ of the nearest downwind site and about $50 \%$ of the levels observed at $100 \mathrm{~m}$ from the road.

To compare the variation in background concentrations estimated using the spline-of-minimums method, the mean background value for each run was calculated and the between-run standard deviation (SD) was determined from the resulting 24 mean background values. Additionally, the within-run SDs of the estimated background concentrations were calculated by first calculating the SD of the background concentrations for each run and then taking the range of those values (Table 3). The large differences in within-run SD are likely due to variations in meteorological conditions. For this reason, the range is given instead of the mean. For $\mathrm{CO}$ and $\mathrm{NO}_{2}$, the between-run SD was greater than all of the withinrun SDs (Table 3), indicating that the between run variation of these pollutants was greater than the hourly variation. For the rest of the pollutants measured, the between-run SD fell within the range of the within-run SD.

\subsection{Temporal and spatial smoothing methods}

The influence of temporal and spatial smoothing on the estimates of the $\mathrm{NO}_{2}$ concentration gradient along the $900 \mathrm{~m}$ highway transect in route B (analyzed in Sect. 3.1) was also compared. The data shown were collected on 21 September 2012 and 11 October 2012, comprising a total of 26 laps, and were filtered using the COV method (Hagler et al., 2012). On 21 September 2012 winds were generally calm, with a mean wind speed of $0.4 \mathrm{~m} \mathrm{~s}^{-1}$. On 11 October 2012 winds were slightly stronger and generally from the highway, with a mean wind speed of $0.56 \mathrm{~m} \mathrm{~s}^{-1}$ and mean wind direction of $285^{\circ}$ (from the NW). The model $\mathrm{NO}_{2}=m \times \log ($ distance $)+b$ was fit for each smoothing case because previous studies have found that pollutant concentrations tend to decrease exponentially with distance from a major source (Karner et al., 2010). 


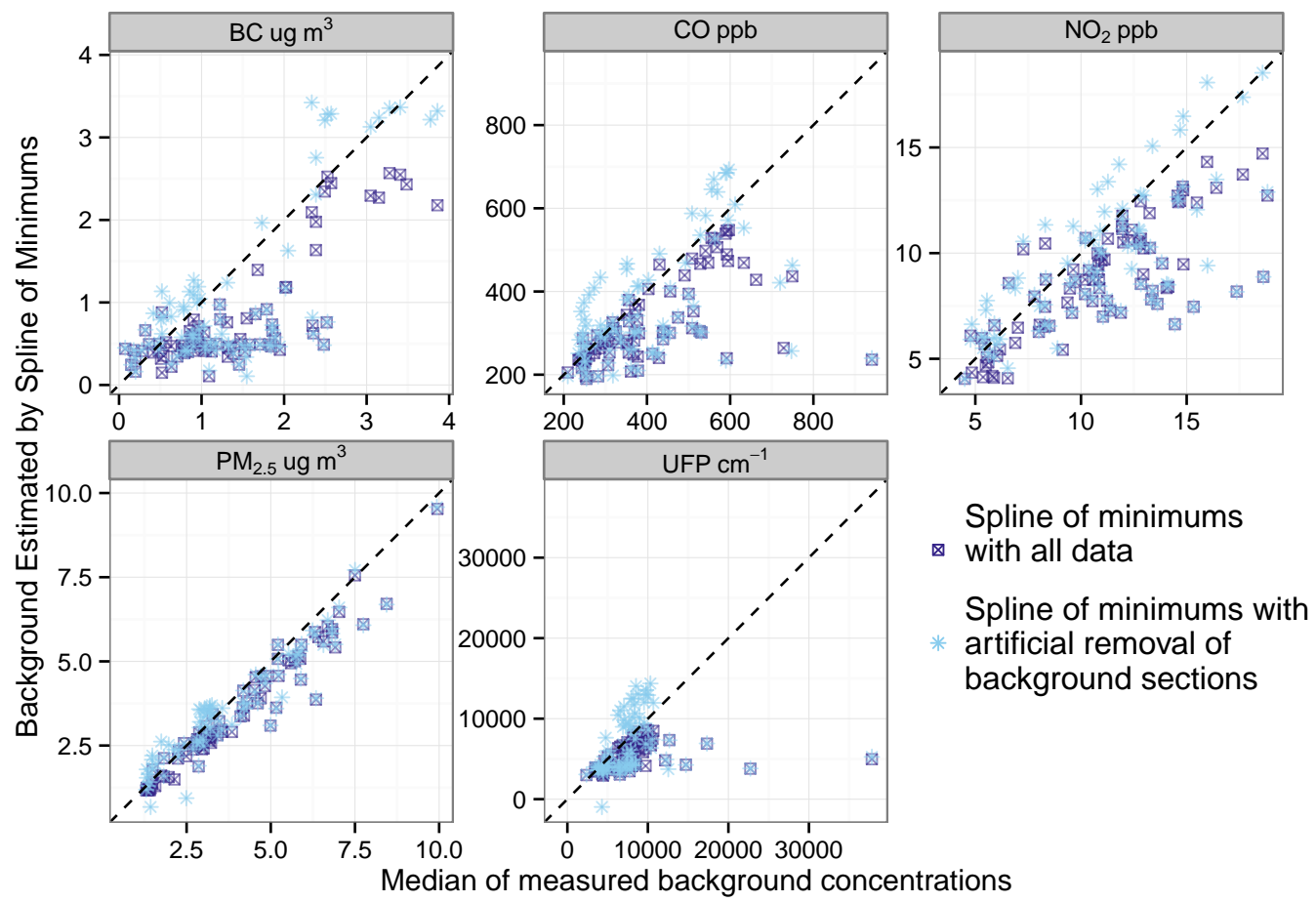

Figure 6. Comparison of location-based (median of measured background concentrations) and time-series-based (spline of minimums) background estimates. Time-series-based estimates were calculated using all of the data and after the measurements in areas designated as background had been removed. Dashed black lines represent $y=x$.

Table 3. Summary comparison of pollutant background concentration and variation.

\begin{tabular}{lcccc}
\hline & Mean of background & Within-run SD ${ }^{\mathrm{a}, \mathrm{b}}$ & Between-run SD $^{\mathrm{c}}$ & $\begin{array}{l}\text { Contribution of } \\
\text { background to } \\
\text { total }\end{array}$ \\
\hline $\mathrm{BC}\left(\mu \mathrm{g} \mathrm{m}^{-3}\right)$ & 0.48 & $0.01-0.50$ & 0.40 & $15 \%$ \\
$\mathrm{UFPs}\left(\mathrm{cm}^{-3}\right)$ & 4990 & $20-2620$ & 1570 & $26 \%$ \\
$\mathrm{CO}(\mathrm{ppb})$ & 298 & $3-57$ & 75 & $41 \%$ \\
$\mathrm{NO}_{2}(\mathrm{ppb})$ & 8.8 & $0.1-2.2$ & 2.4 & $57 \%$ \\
$\mathrm{PM}_{10}\left(\mu \mathrm{g} \mathrm{m}^{-3}\right)$ & 6.1 & $0.1-2.9$ & 2.0 & $60 \%$ \\
$\mathrm{PM}_{2.5}\left(\mu \mathrm{g} \mathrm{m}^{-3}\right)$ & 3.7 & $0.1-2.6$ & 1.6 & $68 \%$ \\
\hline
\end{tabular}

a Standard deviation, ${ }^{\mathrm{b}}$ calculated by first calculating the SD of the estimated background for each run and then taking the range of those values, ${ }^{\mathrm{c}}$ calculated by determining the mean background value for each run and determining the standard deviation of the resulting 24 mean background values, and ${ }^{\mathrm{d}}$ mean of estimated background for all 24 runs divided by mean measured concentration of all runs multiplied by 100 .

When compared to the raw data (Fig. 8a), spatial smoothing alone clarified the spatial trend (Fig. 8b). In contrast, although temporal smoothing reduces the number of data points, the spatial trend was still obscured (Fig. 8c). Furthermore, while spatial smoothing alone resulted in a fairly smooth gradient and the degree of spatial smoothing did not have a significant effect on the fitted curve (Fig. 8b), aggregating the data to a larger timescale before applying spatial smoothing introduces additional variation (Fig. 8d). This variation is due to the error introduced into the estimation of location by using a longer timescale. The slight increase in concentrations at $500 \mathrm{~m}$ is due to a busy intersection at this location.

The same data set comprising 26 laps was used to compare the effect of smoothing on pollutant correlations. The results indicated that both spatial and temporal smoothing causes pollutant concentrations to become more correlated as measured by the Spearman correlation coefficients (Table 4). The average speed of the car on this route was approximately $10 \mathrm{~m} \mathrm{~s}^{-1}$. The Spearman correlation coefficients were calculated for $\mathrm{BC}, \mathrm{CO}, \mathrm{NO}_{2}, \mathrm{PM}_{2.5}$, and UFPs after applying the COV filter (Hagler et al., 2012) and after 


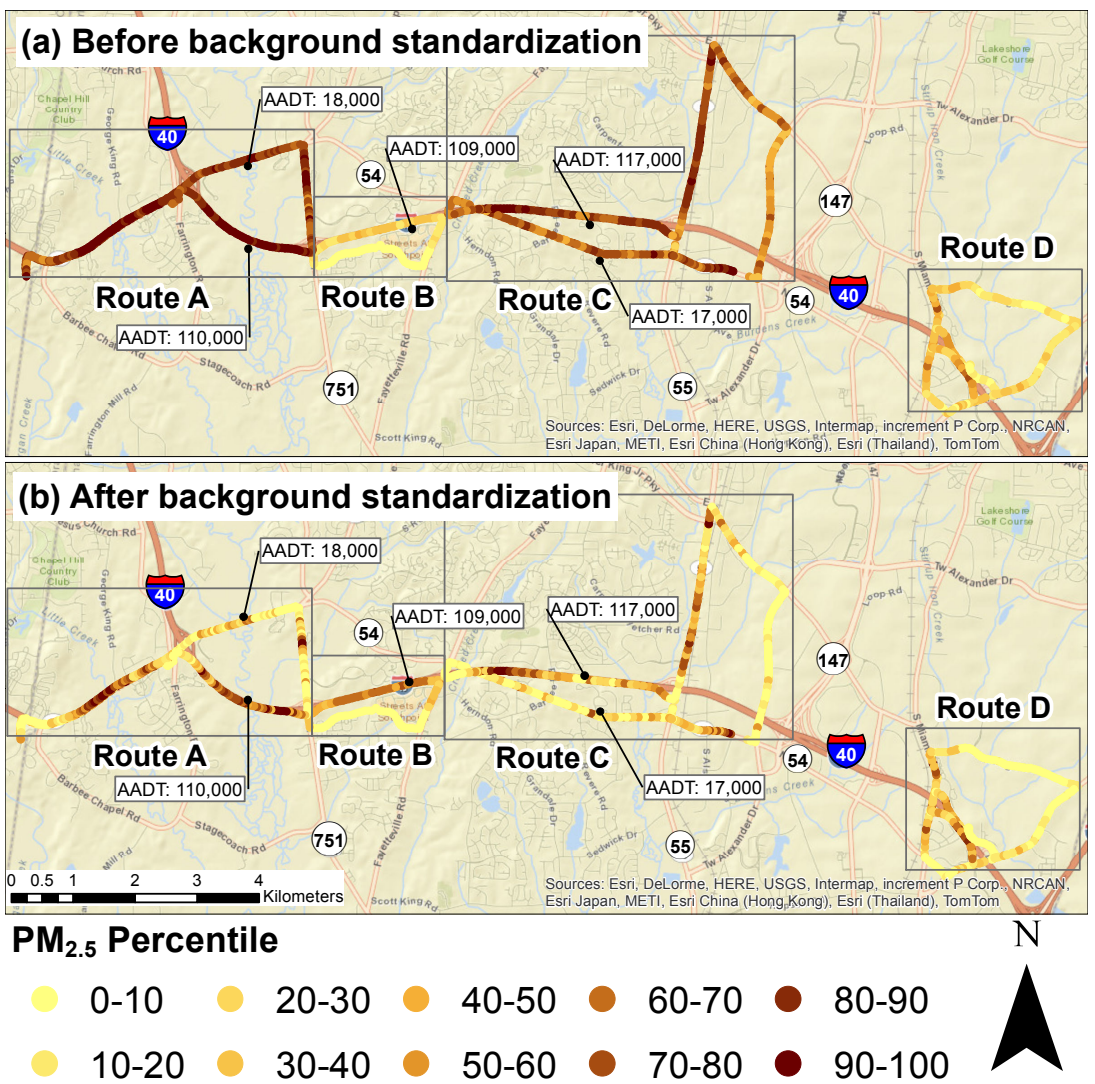

Figure 7. Spatial distribution of $\mathrm{PM}_{2.5}$ before (a) and after (b) background standardization. Points represent median $50 \mathrm{~m}$ values from eight sampling runs with each route measured on two days. Points are colored by $\mathrm{PM}_{2.5}$ percentile.

Table 4. Effect of temporal and spatial smoothing on pollutant Spearman correlation coefficients.

\begin{tabular}{|c|c|c|c|c|c|c|}
\hline & \multirow[b]{2}{*}{ Filtered raw data } & \multicolumn{2}{|c|}{ Temporal smoothing } & \multicolumn{3}{|c|}{ Spatial smoothing } \\
\hline & & $5 s$ & $10 \mathrm{~s}$ & $10 \mathrm{~m}$ & $50 \mathrm{~m}$ & $100 \mathrm{~m}$ \\
\hline & $N=8386$ & $N=1801$ & $N=921$ & $N=529$ & $N=105$ & $N=52$ \\
\hline $\mathrm{NO}_{2}(\mathrm{ppb})$ and $\mathrm{PM}_{2.5}\left(\mu \mathrm{g} \mathrm{m}^{-3}\right)$ & 0.07 & 0.10 & 0.12 & 0.77 & 0.85 & 0.86 \\
\hline $\mathrm{NO}_{2}(\mathrm{ppb})$ and $\mathrm{BC}\left(\mu \mathrm{g} \mathrm{m}^{-3}\right)$ & 0.11 & 0.12 & 0.12 & 0.76 & 0.81 & 0.80 \\
\hline $\mathrm{CO}(\mathrm{ppb})$ and $\mathrm{NO}_{2}(\mathrm{ppb})$ & 0.16 & 0.18 & 0.18 & 0.81 & 0.85 & 0.85 \\
\hline UFPs $\left(\mathrm{cm}^{-3}\right)$ and $\mathrm{PM}_{2.5}\left(\mu \mathrm{g} \mathrm{m}^{-3}\right)$ & 0.41 & 0.53 & 0.57 & 0.83 & 0.89 & 0.89 \\
\hline UFPs $\left(\mathrm{cm}^{-3}\right)$ and $\mathrm{BC}\left(\mu \mathrm{g} \mathrm{m}^{-3}\right)$ & 0.47 & 0.53 & 0.58 & 0.80 & 0.85 & 0.86 \\
\hline $\mathrm{BC}\left(\mu \mathrm{g} \mathrm{m}^{-3}\right)$ and $\mathrm{PM}_{2.5}\left(\mu \mathrm{g} \mathrm{m}^{-3}\right)$ & 0.54 & 0.69 & 0.74 & 0.77 & 0.82 & 0.84 \\
\hline $\mathrm{NO}_{2}(\mathrm{ppb})$ and UFPs $\left(\mathrm{cm}^{-3}\right)$ & 0.56 & 0.60 & 0.62 & 0.88 & 0.87 & 0.87 \\
\hline $\mathrm{CO}(\mathrm{ppb})$ and UFPs $\left(\mathrm{cm}^{-3}\right)$ & 0.58 & 0.63 & 0.65 & 0.88 & 0.92 & 0.92 \\
\hline $\mathrm{CO}(\mathrm{ppb})$ and $\mathrm{PM}_{2.5}\left(\mu \mathrm{g} \mathrm{m}^{-3}\right)$ & 0.61 & 0.73 & 0.76 & 0.84 & 0.86 & 0.86 \\
\hline $\mathrm{CO}(\mathrm{ppb})$ and $\mathrm{BC}\left(\mu \mathrm{g} \mathrm{m}^{-3}\right)$ & 0.69 & 0.74 & 0.76 & 0.81 & 0.85 & 0.87 \\
\hline
\end{tabular}

calculating 5 and $10 \mathrm{~s}$ averages (discrete windows), dividing the route into 10,50 , and $100 \mathrm{~m}$ segments, and calculating the average of the measurements in each segment. Spatial smoothing resulted in much stronger correlations compared to temporal smoothing (Table 4). After $10 \mathrm{~m}$ averaging, all of the pollutants were correlated with coefficients greater than
0.7. After $50 \mathrm{~m}$ averaging, all of the correlation coefficients were greater than 0.8 , but increasing the averaging interval to $100 \mathrm{~m}$ did not change any coefficients by more than 0.02 . Spatial smoothing results in a smaller sample size used to determine the correlations compared with temporal smoothing due to the repeated laps. While a smaller sample size does 


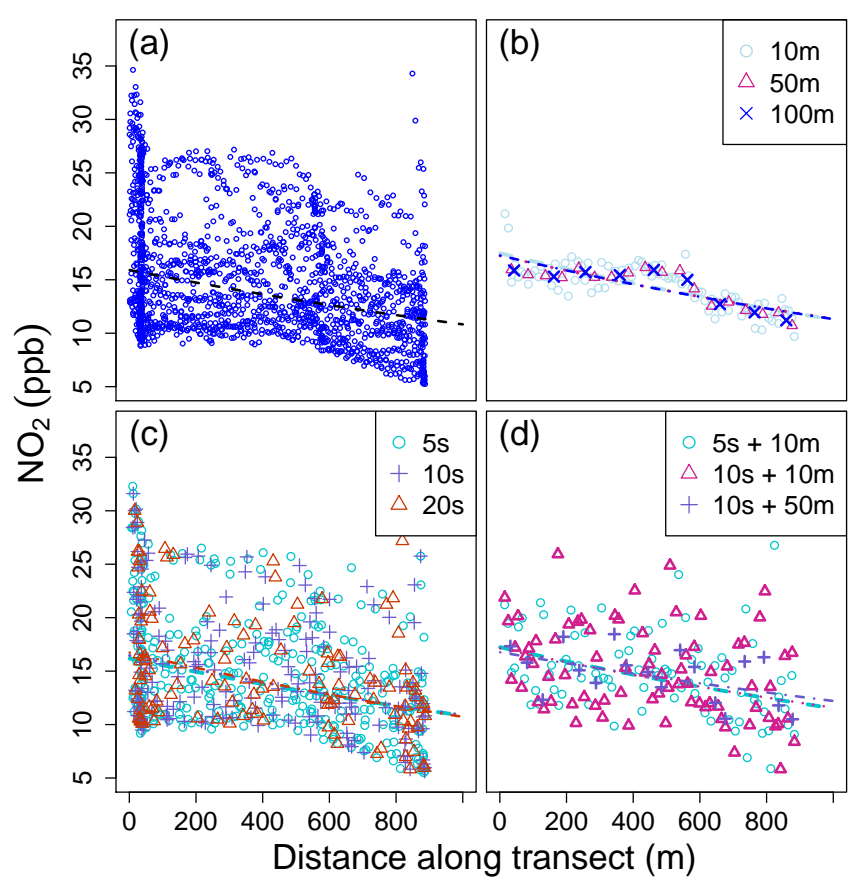

Figure 8. Comparison of the effect of temporal and spatial smoothing on $\mathrm{NO}_{2}$ measurements collected on the $900 \mathrm{~m}$ transect of route $\mathrm{B}$, shown in Fig. 3, by distance from the highway: (a) raw data; (b) data after spatial smoothing by calculating mean concentrations by 10,50 , and $100 \mathrm{~m}$ route segments; (c) data after temporal smoothing by calculating discrete 5, 10, and $20 \mathrm{~s}$ averages; and (d) data after combination of temporal and spatial smoothing. The model $\mathrm{NO}_{2}=m \times \log$ (distance $)+b$ was fit for each smoothing case. The regression lines are plotted with the respective data and the color corresponds with the points used.

not necessarily lead to higher correlation, this study demonstrates that spatial versus temporal averaging of mobile air monitoring observations does appear to provide higher correlation values. The results indicate that spatial averaging may more clearly isolate trends of higher versus lower air pollution environments (highways versus background).

\section{Conclusions}

The recent increase in the number of studies that employ mobile monitoring and the variety of applications demonstrate both the utility and versatility of mobile monitoring. As air monitoring instrumentation continues to advance toward greater portability, higher time resolution, greater capacity for operating autonomously, and lower costs, it is likely that these types of studies will become even more ubiquitous (Snyder et al., 2013). The greater temporal and geographic coverage of air pollution measurements can in turn lead to better protection of health and the environment. However, as was shown in this study, this new wealth of data requires the implementation of innovative data-processing techniques to extract meaningful information and develop intuitive visuals.
This study investigated the sensitivity of final analysis results to the data-processing steps chosen.

A variety of research questions and the corresponding data-processing strategies were discussed, and a framework for deciding which strategies to apply was presented. Removing the influence of local exhaust plumes can substantially change a near-source gradient, but the various methods compared resulted in similar results. A times-series based method for estimating background concentrations was compared with the location-based estimation of background. The time-series-based method was found to slightly underestimate the background concentrations when compared with the location-based method, possibly due to traffic in the designated background areas. Background standardization was particularly important for pollutants with a high background concentration relative to the total concentration, and estimated background concentrations were shown to vary with time. Spatial averaging $(50 \mathrm{~m})$ resulted in smoother concentration gradients and stronger correlations than temporal averaging (5s).

The results demonstrate the vast amount of information contained in data sets collected using mobile monitoring and the myriad of research questions that can be answered using these data, as well as the sensitivity of the conclusions to the data-processing approach utilized.

Acknowledgements. This research would not have been possible without the careful field measurements conducted by ARCADIS employee Parikshit Deshmukh under contract EP-C-09-027. The authors are also grateful for the research support provided by a number of EPA staff in the Office of Research and Development, particularly Richard Shores, Bill Mitchell, and Robert Wright.

Edited by: G. Phillips

Disclaimer. This document has been reviewed in accordance with the US Environmental Protection Agency policy and approved for publication. Mention of trade names or commercial products does not constitute endorsement or recommendation for use. The views expressed in this journal article are those of the authors and do not necessarily reflect the views or policies or the US Environmental Protection Agency.

\section{References}

Adams, M. D., DeLuca, P. F., Corr, D., and Kanaroglou, P. S.: Mobile Air Monitoring: Measuring Change in Air Quality in the City of Hamilton, 2005-2010, Social Indicators Res., 108, 351-364, 2012.

Arku, R. E., Vallarino, J., Dionisio, K. L., Willis, R., Choi, H., Wilson, J. G., Hemphill, C., Agyei-Mensah, S., Spengler, J. D., and Ezzati, M.: Characterizing air pollution in two low-income neighborhoods in Accra, Ghana, Sci. Total Environ., 402, 217 231, 2008. 
Baldauf, R., Thoma, E., Khlystov, A., Isakov, V., Bowker, G., Long, T., and Snow, R.: Impacts of noise barriers on near-road air quality, Atmos. Environ., 42, 7502-7507, 2008.

Bukowiecki, N., Dommen, J., Prevot, A., Richter, R., Weingartner, E., and Baltensperger, U.: A mobile pollutant measurement laboratory-measuring gas phase and aerosol ambient concentrations with high spatial and temporal resolution, Atmos. Environ., 36, 5569-5579, 2002.

Carslaw, D. C. and Ropkins, K.: openair - An R package for air quality data analysis, Environ. Model. Softw., 27-28, 52-61, 2012.

Choi, W., He, M., Barbesant, V., Kozawa, K. H., Mara, S., Winer, A. M., and Paulson, S. E.: Prevalence of wide area impacts downwind of freeways under pre-sunrise stable atmospheric conditions, Atmos. Environ., 62, 318-327, doi:10.1016/j.atmosenv.2012.07.084, 2012.

Dionisio, K. L., Rooney, M. S., Arku, R. E., Friedman, A. B., Hughes, A. F., Vallarino, J., Agyei-Mensah, S., Spengler, J. D., and Ezzati, M.: Within-neighborhood patterns and sources of particle pollution: mobile monitoring and geographic information system analysis in four communities in Accra, Ghana, Environ. Health Perspect., 118, 607-613, doi:10.1289/ehp.0901365, 2010.

Drewnick, F., Böttger, T., von der Weiden-Reinmüller, S.-L., Zorn, S. R., Klimach, T., Schneider, J., and Borrmann, S.: Design of a mobile aerosol research laboratory and data processing tools for effective stationary and mobile field measurements, Atmos. Meas. Tech., 5, 1443-1457, doi:10.5194/amt-5-1443-2012, 2012.

Durant, J. L., Ash, C. A., Wood, E. C., Herndon, S. C., Jayne, J. T., Knighton, W. B., Canagaratna, M. R., Trull, J. B., Brugge, D., Zamore, W., and Kolb, C. E.: Short-term variation in nearhighway air pollutant gradients on a winter morning, Atmos. Chem. Phys., 10, 8341-8352, doi:10.5194/acp-10-8341-2010, 2010.

ESRI: ArcGIS Desktop: Release 10, Environmental Systems Research Institute, Redlands, CA, USA, 2011.

Farrell, P., Culling, D., and Leifer, I.: Transcontinental Methane Measurements: Part 1. A Mobile Surface Platform for Source Investigations, Atmos. Environ., 74, 422-431, doi:10.1016/j.atmosenv.2013.02.014, 2013.

Hagler, G., Baldauf, R., Thoma, E., Long, T., Snow, R., Kinsey, J., Oudejans, L., and Gullett, B.: Ultrafine particles near a major roadway in Raleigh, North Carolina: Downwind attenuation and correlation with traffic-related pollutants, Atmos. Environ., 43, 1229-1234, 2009.

Hagler, G., Yelverton, T., Vedantham, R., Hansen, A., and Turner, J.: Post-processing method to reduce noise while preserving high time resolution in aethalometer real-time black carbon data, Aerosol Air Quality Res., 11, 539-546, 2011.

Hagler, G. S. W., Thoma, E. D., and Baldauf, R. W.: HighResolution Mobile Monitoring of Carbon Monoxide and Ultrafine Particle Concentrations in a Near-Road Environment, J. Air Waste Manag. Assoc., 60, 328-336, 2010.

Hagler, G. S. W., Lin, M.-Y., Khlystov, A., Baldauf, R. W., Isakov, V., Faircloth, J., and Jackson, L. E.: Field investigation of roadside vegetative and structural barrier impact on near-road ultrafine particle concentrations under a variety of wind conditions, Sci. Total Environ., 419, 7-15, 2012.
Hu, S., Paulson, S. E., Fruin, S., Kozawa, K., Mara, S., and Winer, A. M.: Observation of elevated air pollutant concentrations in a residential neighborhood of Los Angeles California using a mobile platform, Atmos. Environ., 51, 311-319, 2012.

Karner, A. A., Eisinger, D. S., and Niemeier, D. A.: Near-roadway air quality: synthesizing the findings from real-world data, Environ. Sci. Technol., 44, 5334-5344, 2010.

Kimbrough, S., Baldauf, R. W., Hagler, G. S., Shores, R. C., Mitchell, W., Whitaker, D. A., Croghan, C. W., and Vallero, D. A.: Long-term continuous measurement of near-road air pollution in Las Vegas: seasonal variability in traffic emissions impact on local air quality, Air Quality, Atmosp. Health, 6, 295305, 2013.

Kolb, C. E., Herndon, S. C., McManus, J. B., Shorter, J. H., Zahniser, M. S., Nelson, D. D., Jayne, J. T., Canagaratna, M. R., and Worsnop, D. R.: Mobile laboratory with rapid response instruments for real-time measurements of urban and regional trace gas and particulate distributions and emission source characteristics, Environ. Sci. Technol., 38, 5694-5703, 2004.

Kozawa, K. H., Fruin, S. A., and Winer, A. M.: Near-road air pollution impacts of goods movement in communities adjacent to the Ports of Los Angeles and Long Beach, Atmos. Environ., 43, 2960-2970, 2009.

Massoli, P., Fortner, E. C., Canagaratna, M. R., Williams, L. R., Zhang, Q., Sun, Y., Schwab, J. J., Trimborn, A., Onasch, T. B., Demerjian, K. L., et al.: Pollution gradients and chemical characterization of particulate matter from vehicular traffic near major roadways: results from the 2009 Queens College Air Quality study in NYC, Aerosol Sci. Technol., 46, 1201-1218, 2012.

MATLAB: version 7.14.0 (R2010a), The MathWorks Inc., Natick, Massachusetts, 2012.

Padró-Martínez, L. T., Patton, A. P., Trull, J. B., Zamore, W., Brugge, D., and Durant, J. L.: Mobile monitoring of particle number concentration and other traffic-related air pollutants in a near-highway neighborhood over the course of a year, Atmos. Environ., 61, 253-264, doi:10.1016/j.atmosenv.2012.06.088, 2012.

Park, S. S., Kozawa, K., Fruin, S., Mara, S., Hsu, Y.-K., Jakober, C., Winer, A., and Herner, J.: Emission factors for high-emitting vehicles based on on-road measurements of individual vehicle exhaust with a mobile measurement platform, J. Air Waste Manag. Assoc., 61, 1046-1056, 2011.

Pirjola, L., Lähde, T., Niemi, J., Kousa, A., Rönkkö, T., Karjalainen, P., Keskinen, J., Frey, A., and Hillamo, R.: Spatial and temporal characterization of traffic emissions in urban microenvironments with a mobile laboratory, Atmos. Environ., 63, 156-167, doi:10.1016/j.atmosenv.2012.09.022, 2012.

Pétron, G., Frost, G., Miller, B. R., Hirsch, A. I., Montzka, S. A., Karion, A., Trainer, M., Sweeney, C., Andrews, A. E., and Miller, L.: Hydrocarbon emissions characterization in the Colorado Front Range: A pilot study, J. Geophys. Res. Atmos., (1984-2012), 117, D04304, doi:10.1029/2011JD016360, 2012.

R Core Team: R: A Language and Environment for Statistical Computing, R Foundation for Statistical Computing, Vienna, Austria, available at: http://www.R-project.org/, ISBN 3-900051-07$0,2012$.

Rooney, M. S., Arku, R. E., Dionisio, K. L., Paciorek, C., Friedman, A. B., Carmichael, H., Zhou, Z., Hughes, A. F., Vallarino, J., and Agyei-Mensah, S.: Spatial and temporal patterns of partic- 
ulate matter sources and pollution in four communities in Accra, Ghana, Sci. Total Environ., 435, 107-114, 2012.

Snyder, E. G., Watkins, T., Solomon, P., Thoma, E., Williams, R., Hagler, G., Shelow, D., Hindin, D., Kilaru, V., and Preuss, P.: The Changing Paradigm of Air Pollution Monitoring, Environ. Sci. Technol., 47, 11369-11377, doi:10.1021/es4022602, 2013.

Van Poppel, M., Peters, J., and Bleux, N.: Methodology for setup and data processing of mobile air quality measurements to assess the spatial variability of concentrations in urban environments, Environ. Pollut., 183, 224-233, doi:10.1016/j.envpol.2013.02.020, 2013.

Wallace, J., Corr, D., Deluca, P., Kanaroglou, P., and McCarry, B.: Mobile monitoring of air pollution in cities: the case of Hamilton, Ontario, Canada, J. Environ. Monitor., 11, 998-1003, 2009.

Wang, X., Westerdahl, D., Chen, L. C., Wu, Y., Hao, J., Pan, X., Guo, X., and Zhang, K. M.: Evaluating the air quality impacts of the 2008 Beijing Olympic Games: On-road emission factors and black carbon profiles, Atmos. Environ., 43, 4535-4543, 2009.

Wang, X., Westerdahl, D., Wu, Y., Pan, X., and Zhang, K. M.: Onroad emission factor distributions of individual diesel vehicles in and around Beijing, China, Atmos. Environ., 45, 503-513, 2011.

Wang, X., Westerdahl, D., Hu, J., Wu, Y., Yin, H., Pan, X., and Max Zhang, K.: On-road diesel vehicle emission factors for nitrogen oxides and black carbon in two Chinese cities, Atmos. Environ., 46, 45-55, 2012.
Weijers, E., Khlystov, A., Kos, G., and Erisman, J.: Variability of particulate matter concentrations along roads and motorways determined by a moving measurement unit, Atmos. Environ., 38, 2993-3002, 2004.

Westerdahl, D., Fruin, S., Sax, T., Fine, P. M., and Sioutas, C.: Mobile platform measurements of ultrafine particles and associated pollutant concentrations on freeways and residential streets in Los Angeles, Atmos. Environ., 39, 3597-3610, 2005.

Westerdahl, D., Wang, X., Pan, X., and Zhang, K. M.: Characterization of on-road vehicle emission factors and microenvironmental air quality in Beijing, China, Atmos. Environ.t, 43, 697-705, 2009.

Wickham, H.: ggplot2: elegant graphics for data analysis, Springer New York, available at: http://had.co.nz/ggplot2/book, 2009.

Wood, S. N.: Thin-plate regression splines, J. Roy. Stat. Soc., 65, 95-114, 2003.

Yamartino, R.: A comparison of several "single-pass" estimators of the standard deviation of wind direction, J. Climate Appl. Meteorol., 23, 1362-1366, 1984.

Zwack, L. M., Paciorek, C. J., Spengler, J. D., and Levy, J. I.: Characterizing local traffic contributions to particulate air pollution in street canyons using mobile monitoring techniques, Atmos. Environ., 45, 2507-2514, 2011a.

Zwack, L. M., Paciorek, C. J., Spengler, J. D., and Levy, J. I.: Modeling spatial patterns of traffic-related air pollutants in complex urban terrain, Environ. Health Perspect., 119, 852-859, doi:10.1289/ehp.1002519, 2011 b. 